\title{
Estudio para instalar una planta de producción de pasta dental utilizando papaína como ingrediente activo
}

\author{
Andrea Natalia Linares Linares* \\ Raiza Katherine Morales Flores** \\ Anlina Consultoría Integral. Lima, Perú \\ Recibido: 5 de setiembre de 2014 / Aprobado: 23 de abril de 2015
}

RESUMEN: En la población es común el uso de pastas dentales con elevada abrasividad para eliminar la placa bacteriana, prevenir enfermedades bucodentales y blanquear los dientes; esto deteriora el esmalte dental, ocasionando problemas de sensibilidad. Por ello, se propone el empleo de la papaína, la cual permite obtener una pasta de baja abrasividad que además de tener actividad antiplaca y antisarro, blanquea las superficies dentales, atacando en su origen a los elementos causantes de la aparición de placa, caries, sarro y manchas dentales. Adicionalmente, permite tratar problemas de hipersensibilidad dentaria, provocados por estímulos externos térmicos (frío o calor), ácidos, sales, azúcares, o táctiles (presión), sobre las terminaciones nerviosas de las piezas dentales.

Palabras clave: papaína / pasta dental / industrialización de materias primas peruanas

\section{Study for the Installation of a Toothpaste's Plant, Using Papain as Active Ingredient}

\begin{abstract}
Aвstract: People today consume high abrasiveness toothpastes to remove the plaque from, to prevent oral diseases and whiten your teeth. This deteriorates tooth enamel, causing sensitivity problems. In this regard, the use of papain is proposed, which allows to elaborate a paste of low abrasiveness that not only presents antiplaque and anti-scale activity but also a whitening activity of dental surfaces, which attacks the causes for the appearance of plate elements, caries, tartar and dental stains. In addition, allows to treat problems of tooth hypersensitivity, induced by external stimuli, such as thermal (hot or cold), acids, salts, sugars, or tactile (pressure), about from the trigeminal nerve endings, located in the dentin.
\end{abstract}

Key words: papain / toothpaste / industrialization of Peruvian raw materials

Correos electrónicos: *andrea.n.linares@gmail.com, **raiza0720@gmail.com 


\section{ANTECEDENTES Y PROBLEMAS DE LA INVESTIGACIÓN}

Es de vital importancia mantener en condiciones saludables la cavidad oral, con el fin de evitar que microorganismos presentes en infecciones de origen bucal pasen al interior del organismo y produzcan una patología a distancia. Las investigaciones y evidencias clínicas indican que las infecciones periodontales pueden representar un factor de riesgo para partos prematuros, niños de bajo peso, enfermedades respiratorias, úlceras gástricas, agravamiento de la diabetes y complicaciones en pacientes dializados (Bettina, 2006).

Por otro lado, la limpieza bucal no solo representa una medida de prevención de las enfermedades bucodentales, sino también la base de una buena autoestima, ya que los dientes sanos y blancos le dan un buen aspecto a una persona, hacen que se sienta bien y le permiten hablar y comer apropiadamente.

La condición de la salud bucal en el Perú constituye un problema de salud pública; en lo que se refiere a la caries dental, el índice de dientes cariados, perdidos y obturados (CPOd) en niños de doce años de edad es de aproximadamente seis, y clasifica al país en estado de emergencia, según la Organización Panamericana de la Salud (Dirección General de Salud de las Personas del Ministerio de Salud del Perú, 2011). La incidencia de las enfermedades infecciosas, su consecuente costo en vidas y recursos económicos (OMS, 2006) en las últimas décadas ha hecho que su prevención sea una de las principales preocupaciones de las entidades encargadas de la atención en salud en todo el país. Como en todas las ciencias médicas, su mejor arma es la prevención.

La alteración de la coloración original y natural del diente es un proceso de varias fases (Bonilla, Mantín, Jiménez y Lamas, 2007). En una primera fase se fijan las proteínas salivales que constituyen una placa proteica incipiente, para que luego se produzca la colonización de dicha placa proteica por la placa bacteriana. Entonces, las bacterias transforman los azúcares del medio en largas cadenas de polisacáridos que excretan material capsular, con lo que se aumenta la adherencia al esmalte. Consecutivamente, si esta situación no se corrige, todas estas estructuras se van calcificando lentamente y dan lugar a los cálculos dentales. Los microorganismos van muriendo tras el depósito de sales cálcicas pero en la superficie siguen fijándose más proteínas salivales y microorganismos, con lo que los cálculos dentales siguen creciendo de manera continua, hasta llegar a formar caries. 


\section{PAPAÍNA, INGREDIENTE ACTIVO}

La papaína es una cisteína proteasa de la familia C1 peptidasa. Esta enzima se compone de una única cadena polipeptídica, con tres puentes disulfuro y un grupo sulfhidrilo.

La papaína es extraída del látex de la Carica papaya (papaya), el cual es recolectado a partir de cortes longitudinales realizados a frutos inmaduros.

A continuación se describen las propiedades físicas de dicha enzima:

Tabla 1

Propiedades físicas de la papaína

\begin{tabular}{ll}
\hline Propiedad & \multicolumn{1}{c}{ Valor } \\
\hline Punto isoeléctrico & $\mathrm{Ph}=8.75$ \\
Constante de sedimentación & $2.42+-0.04 \mathrm{seg}$ \\
Constante de difusión & $10.27+-0.13 \times 10^{7} \mathrm{~cm}^{2} \mathrm{seg}^{-1}$ \\
Peso molecular & 23,350 Daltons \\
Rotación óptica $\left(\mathrm{pH}=5.7,25^{\circ} \mathrm{C}\right)$ & $-66,7$ \\
\hline
\end{tabular}

Fuente: Mundo y Serrano (2012)

Aunque las soluciones de papaína tienen buena estabilidad a la temperatura, esta depende del $\mathrm{pH}$. En condiciones ácidas son inestables, es decir, a valores de $\mathrm{pH}$ por debajo de 2.8 hay una pérdida significativa en la actividad. Para la enzima activa en solución, la pérdida de la actividad es de aproximadamente 1-2 \% por día, probablemente como resultado de la autólisis o la oxidación. Una forma inactiva común de la papaína obtenida durante el aislamiento es una mezcla de disulfuro formado entre el grupo sulfhidrilo, sitio activo de la proteína y la cisteína libre (Sigma-Aldrich, 2013).

El comercio de esta enzima se ha expandido a través de los años debido a sus múltiples aplicaciones industriales. En el Perú es utilizada en el ablandamiento de carne y como aclarador de cerveza, dándole mayor o menor tonalidad, según la preferencia (Chullén, 2010). Esta enzima aún no se fabrica en el Perú, motivo por el cual tendrá que ser importada para la ejecución del proyecto.

La papaína es utilizada en la elaboración de la pasta dental en estudio debido a que actúa directamente sobre los cúmulos de la placa 


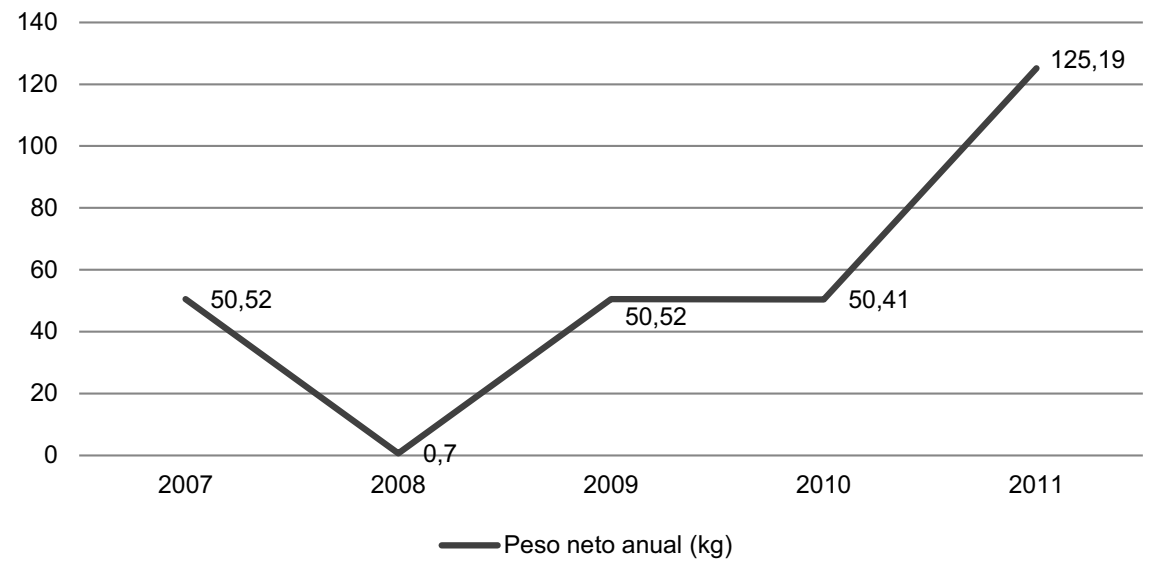

Figura 1. Importaciones de papaína $(\mathrm{kg})$

Fuente: Sunat (2012)

Elaboración propia

proteica y bacteriana y sobre el cálculo dental, sin alterar el esmalte dental, garantizando un $\mathrm{pH}$ neutro, que no solo permite la acción de los componentes, sino que además protege la hidroxiapatita del esmalte de una desmineralización provocada por ambientes ácidos (Casto, 2005).

\section{JUSTIFICACIÓN DE LA INVESTIGACIÓN}

Desde el punto de vista técnico, la producción de pasta dental representa un proceso tradicional, cuyas etapas son: verificar la calidad y pesar la materia prima; premezclar y mezclar los insumos; verificar el $\mathrm{pH}$, nivel de flúor y saborizante; dosificar, llenar y sellar la pasta en tubos; finalmente, empaquetar en cajas y verificar la calidad del producto terminado (Vásquez, 1989).

Sin embargo, el uso de papaína como insumo en la formulación del dentífrico sí representa una novedad. En 1996, la Oficina Española de Patentes y Marcas aceptó la solicitud de BioCosmetics de patentar la invención de una pasta dentífrica, blanqueadora, antiplaca y antisarro de baja abrasividad. Once años después, con la patente obtenida por Colgate-Palmolive: "Composición oral que permite una mayor eliminación de manchas de los dientes”, se confirmó la efectividad de la 
enzima. Actualmente, España cuenta con empresas productoras y comercializadoras de pasta dental fabricada con papaína: Dentiblanc Laboratorios, Dent Vital, Normodent y Foramen. En el ámbito nacional, en Arequipa, el Centro Interdisciplinario de Investigación e Innovación (CICA), de la Universidad Católica de Santa María (UCSM), desarrolló en 2009 el gel Renova Caries.

Por otro lado, cabe recalcar que la demanda del producto en estudio no solo está asegurada por la tendencia creciente del interés de las personas por el cuidado personal y la constante tasa de crecimiento poblacional del Perú del 1,14 \% (Ipsos Apoyo, 2011), sino también por la medida preventiva contra enfermedades de la cavidad bucal. La Organización Mundial de la Salud afirma que para muchos países de ingresos altos, el 5 al $10 \%$ del gasto sanitario público guarda relación con la salud bucodental.

Entre los beneficios sociales que se esperan obtener se encuentra la instalación de la planta productora de pasta dental, la cual significará una fuente de empleo para los directamente involucrados en el proceso productivo como también para todos los participantes de la cadena de suministro. Asimismo, se busca incentivar el cultivo de Carica papaya en nuestro país, con la finalidad de sustituir la importación de materias primas por la industrialización de productos con valor agregado, fabricados con insumos peruanos (Favero, Bernal y Yácono, 2008). Finalmente, con el fin de brindar una medida preventiva ante enfermedades bucodentales, las que se sitúan en cuarto lugar en lo que respecta a los costos de sus tratamientos y a la baja de densidad de personal de odontología en el mundo (OMS, 2010).

\section{METODOLOGÍA}

El presente trabajo tiene el carácter de investigación aplicada, ya que busca predecir un comportamiento específico en una configuración muy específica, dando lugar a la siguiente hipótesis: la instalación en Lima de una planta procesadora de pasta dental fabricada con papaína como ingrediente activo es factible económica y financieramente, pues existe un mercado que va a aceptar el producto y cuya demanda logrará obtener una utilidad y rentabilidad igual o mayor a la esperada por los accionistas, y además es tecnológicamente viable. Las técnicas y herramientas utilizadas para su desarrollo son las indicadas en la tabla 2. 
Tabla 2

Técnicas y herramientas utilizadas en la investigación

\begin{tabular}{|c|c|c|}
\hline $\begin{array}{l}\text { Técnicas y } \\
\text { herramientas }\end{array}$ & Descripción & Aplicación \\
\hline $\begin{array}{l}\text { Análisis de las } \\
\text { cinco fuerzas de } \\
\text { Porter }\end{array}$ & $\begin{array}{l}\text { Marco de reflexión estratégica sistemática } \\
\text { para determinar la rentabilidad de un sector } \\
\text { específico, normalmente con el fin de evaluar } \\
\text { el valor y la proyección futura de empresas } \\
\text { o unidades de negocio que operan en dicho } \\
\text { sector }\end{array}$ & Análisis del sector \\
\hline $\begin{array}{l}\text { Cuestionarios y } \\
\text { encuestas }\end{array}$ & $\begin{array}{l}\text { Sobre la base de fuentes primarias se obtiene } \\
\text { información sobre las necesidades por } \\
\text { satisfacer del mercado meta, precios aceptados } \\
\text { por el mercado objetivo, nivel de aceptación e } \\
\text { intensidad de compra del producto propuesto }\end{array}$ & Estudio de mercado \\
\hline $\begin{array}{l}\text { Estimación } \\
\text { analógica }\end{array}$ & $\begin{array}{l}\text { Utiliza parámetros basados en información } \\
\text { histórica y de juicio experto para estimar la } \\
\text { demanda, oferta y fabricación del producto } \\
\text { propuesto }\end{array}$ & $\begin{array}{l}\text { Determinación de la } \\
\text { demanda interna aparente }\end{array}$ \\
\hline Regresión lineal & $\begin{array}{l}\text { Permite modelar la relación entre una variable } \\
\text { dependiente y las independientes, con la } \\
\text { finalidad de proyectar valores en el tiempo }\end{array}$ & $\begin{array}{l}\text { Cálculo de la demanda } \\
\text { interna aparente (DIA) y de } \\
\text { la del proyecto }\end{array}$ \\
\hline $\begin{array}{l}\text { Matriz de } \\
\text { enfrentamiento }\end{array}$ & $\begin{array}{l}\text { Herramienta que permite evaluar la } \\
\text { importancia de cada factor respecto a otro }\end{array}$ & $\begin{array}{l}\text { Selección de macro y } \\
\text { microlocalización }\end{array}$ \\
\hline Juicio experto & $\begin{array}{l}\text { Guiado por información histórica, proporciona } \\
\text { información de fuentes primarias sobre } \\
\text { diversos temas. Se suele realizar a través de } \\
\text { consultores o de entrevistas con especialistas. }\end{array}$ & $\begin{array}{l}\text { Selección de estrategias } \\
\text { de marketing, disposición } \\
\text { de planta, fuentes de } \\
\text { financiación, entre otros. }\end{array}$ \\
\hline $\begin{array}{l}\text { Diagrama de } \\
\text { operaciones y } \\
\text { procesos (DOP) }\end{array}$ & $\begin{array}{l}\text { Es una representación gráfica de la secuencia } \\
\text { de actividades que dan valor agregado a } \\
\text { un producto hasta obtener el producto final, } \\
\text { considera los insumos, mermas y reprocesos }\end{array}$ & $\begin{array}{l}\text { Descripción del proceso } \\
\text { productivo para la obtención } \\
\text { del producto en estudio }\end{array}$ \\
\hline Balance de materia & $\begin{array}{l}\text { Se basa en la ley de conservación de la } \\
\text { materia }\end{array}$ & $\begin{array}{l}\text { Cantidad de insumos que } \\
\text { se necesita }\end{array}$ \\
\hline Balance de línea & $\begin{array}{l}\text { De una línea de fabricación equilibrada } \\
\text { depende la optimización de ciertas variables, } \\
\text { que afectan la productividad de un proceso }\end{array}$ & $\begin{array}{l}\text { Identificación del cuello de } \\
\text { botella }\end{array}$ \\
\hline $\begin{array}{l}\text { Análisis de peligros } \\
\text { y puntos críticos de } \\
\text { control (APPCC) }\end{array}$ & $\begin{array}{l}\text { Método que permite garantizar la inocuidad } \\
\text { alimentaria. Considera la implementación de } \\
\text { buenas prácticas de manufactura (BPM) y } \\
\text { procedimientos operativos estandarizados de } \\
\text { saneamiento (POES) }\end{array}$ & $\begin{array}{l}\text { Identificación de los puntos } \\
\text { críticos de control del } \\
\text { proceso productivo }\end{array}$ \\
\hline $\begin{array}{l}\text { Matriz de causa- } \\
\text { efecto o de } \\
\text { Leopold }\end{array}$ & $\begin{array}{l}\text { Consiste en un listado de acciones y otro de } \\
\text { indicadores de impacto ambiental, que se } \\
\text { relacionan en un diagrama matricial }\end{array}$ & $\begin{array}{l}\text { Determinación de impactos } \\
\text { ambientales }\end{array}$ \\
\hline
\end{tabular}


(continuación)

\begin{tabular}{|c|c|c|}
\hline $\begin{array}{l}\text { Técnicas y } \\
\text { herramientas }\end{array}$ & Descripción & Aplicación \\
\hline $\begin{array}{l}\text { Matriz de } \\
\text { identificación de } \\
\text { peligros y riesgos } \\
\text { (IPER) }\end{array}$ & $\begin{array}{l}\text { Esta matriz permite identificar, cuantificar y } \\
\text { priorizar los peligros y los riesgos de cada } \\
\text { etapa de un proceso o actividad }\end{array}$ & $\begin{array}{l}\text { Identificación de los peligros } \\
\text { y riesgos de cada actividad }\end{array}$ \\
\hline $\begin{array}{l}\text { Análisis de } \\
\text { Guerchet }\end{array}$ & $\begin{array}{l}\text { A partir de fórmulas se calcula el espacio total } \\
\text { requerido sobre la base de la suma de tres } \\
\text { superficies parciales: estática, gravitacional y } \\
\text { evolutiva }\end{array}$ & Cálculo de superficies \\
\hline $\begin{array}{l}\text { Análisis y diagrama } \\
\text { relacional }\end{array}$ & $\begin{array}{l}\text { Sobre la base de las vinculaciones entre áreas } \\
\text { se establece su cercanía }\end{array}$ & Disposición de planta \\
\hline $\begin{array}{l}\text { Factores de Peter } \\
\text { \& Timmerhaus }\end{array}$ & $\begin{array}{l}\text { A partir de la clasificación de procesos sólidos, } \\
\text { líquidos o mixtos, y del costo total de los } \\
\text { equipos instalados, se selecciona los factores } \\
\text { que permiten la estimación de los costos de } \\
\text { implementación del proyecto }\end{array}$ & $\begin{array}{l}\text { Estimación de la inversión } \\
\text { total }\end{array}$ \\
\hline $\begin{array}{l}\text { Análisis de } \\
\text { sensibilidad }\end{array}$ & $\begin{array}{l}\text { Busca determinar cómo es afectada la } \\
\text { rentabilidad de un proyecto, cuando una o } \\
\text { varias variables que conforman los supuestos, } \\
\text { bajo los cuales se elaboraron las proyecciones } \\
\text { financieras, se modifican }\end{array}$ & $\begin{array}{l}\text { Evaluación de la } \\
\text { rentabilidad del proyecto }\end{array}$ \\
\hline
\end{tabular}

Elaboración propia

\section{RESULTADOS Y DISCUSIÓN}

\subsection{Estudio de mercado}

Del estudio de mercado realizado se obtuvo los siguientes resultados:

- La segmentación geográfica está delimitada a Lima, debido a que esta representa aproximadamente el $30 \%$ de la población nacional, el mayor porcentaje de la población económicamente activa y la mayor presencia de los niveles socioeconómicos (NSE) A y B elegidos como mercado objetivo del proyecto.

- La segmentación demográfica está orientada a niños mayores de seis años y adultos, sin importar el sexo. La normativa vigente exige que las pastas dentales con concentraciones mayores a $1,100 \mathrm{ppm}$ de flúor deben ser restringidos en niños menores de seis años, a menos que sean recomendadas por un odontólogo.

- La segmentación psicográfica, siguiendo los estilos de vida planteados por Arellano Marketing, está representada por los consumidores afortunados, progresistas y modernos, los cuales representan 
el $54 \%$ de la población limeña. Sin embargo, al no contar con el porcentaje correspondiente a cada NSE, se optó por realizar una encuesta no probabilística. Así, el producto propuesto obtuvo un $80 \%$ de aceptación de compra y un $70 \%$ de intensidad de compra, que da un equivalente a $56 \%$.

- La segmentación socioeconómica fue determinada con base en el precio del producto. Al ser este superior al del promedio, el producto será dirigido a los niveles socioeconómicos A y B, los cuales representan el $21 \%$ de peruanos, según Ipsos Apoyo (2011).

\subsection{Determinación de la demanda}

La demanda interna aparente (DIA) fue calculada considerando la cantidad de pasta dental producida, importada y exportada entre los años 2007 y 2011. Dicha información permitió proyectar los valores para los años 2012 al 2016.

Tabla 3

Demanda del proyecto

\begin{tabular}{ccccc}
\hline Año & $\begin{array}{c}\text { Proyección DIA } \\
\mathbf{( k g )}\end{array}$ & $\begin{array}{c}\text { Demanda del } \\
\text { proyecto }(\mathbf{k g})\end{array}$ & $\begin{array}{c}\text { Demanda del } \\
\text { proyecto (tubos) }\end{array}$ & $\begin{array}{c}\text { Demanda } \\
\text { potencial (kg) }\end{array}$ \\
\hline 2012 & 12433087 & 386572 & 4295249 & 18363499 \\
2013 & 13063380 & 406170 & 4512996 & 18653690 \\
2014 & 13693674 & 425767 & 4730743 & 21577541 \\
2015 & 14323967 & 445364 & 4948490 & 21825835 \\
2016 & 14954261 & 464961 & 5166237 & 22958198 \\
\hline
\end{tabular}

Fuente: Ministerio de la Producción (2012), Sunat (2012), Ipsos Apoyo (2011)

Elaboración propia

\subsection{Comercialización y distribución}

La comercialización y distribución se realizaría a través de dos grandes distribuidores, como Química Suiza y Alfaro, los cuales distribuirían a mayoristas y detallistas, obteniendo un $10 \%$ de ganancia sobre el valor de venta del producto terminado. Siguiendo el canal hasta el cliente final, los mayoristas y detallistas obtendrían entre 25 y $29 \%$ de ganancia sobre el precio al que fue adquirido. El productor venderá también directamente a otros detallistas, otorgándoles un $35 \%$ sobre el valor de venta del producto terminado. 


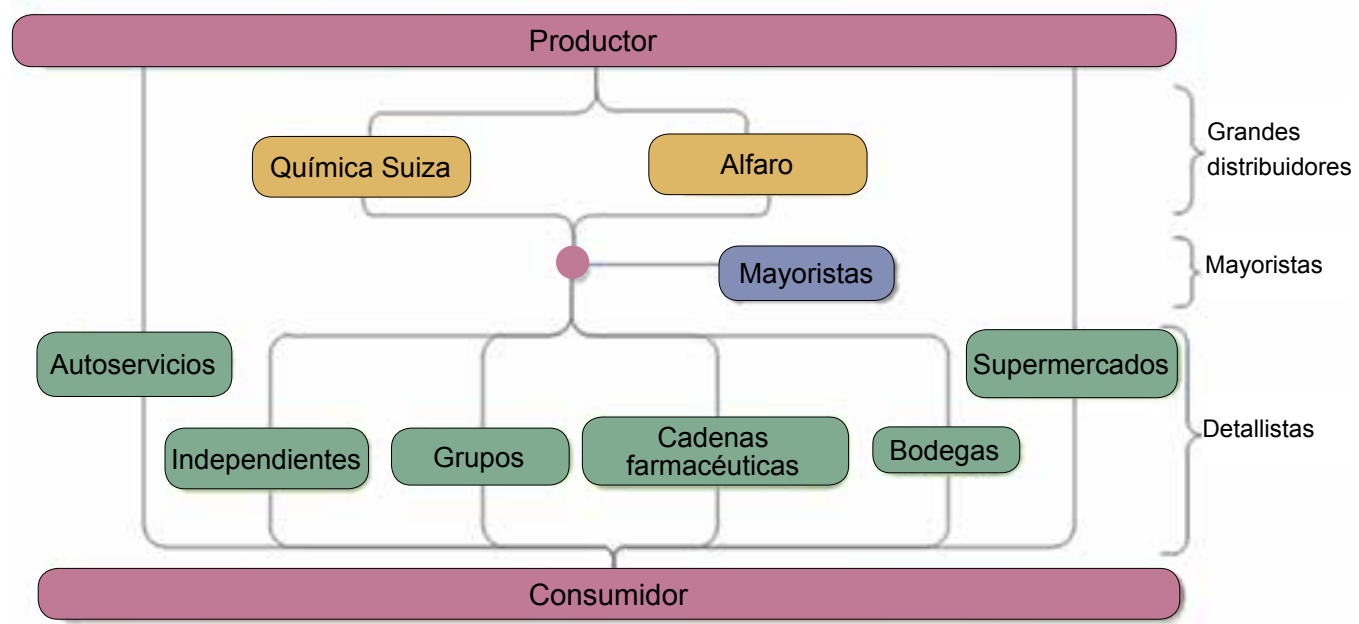

Figura 2. Canales de comercialización y distribución Elaboración propia

\subsection{Marketing y publicidad}

Se determinó que el producto propuesto requiere de una estrategia de diferenciación basada en sus atributos. Toda decisión de compra presenta un lado emocional y un lado racional. El lado emocional está conformado por la nacionalidad del producto (peruano), y por los aspectos de cuidado medioambiental considerados en el proyecto, mientras que el lado racional está reforzado por las enzimas naturales utilizadas para la fabricación y por la importancia del uso de pasta dental para la higiene bucal. Sobre las técnicas de publicidad que se aplicarán, la estrategia incluye el uso de BTL por el primero y el segundo año de venta, que permite detallar los beneficios del producto con campañas educativas, pancartas o la entrega de muestras en colegios, clubes y centros comerciales. Se espera llegar al Brand Awareness en el tercer año, a partir del cual se aplicará BTL y ATL en paralelo. El ATL incluye publicidad a través de comerciales en televisión.

\subsection{Macro y microlocalización}

En el análisis de macrolocalización se consideraron a Lima, Chimbote e Ica como alternativas, y los siguientes factores: proximidad a la materia prima, cercanía al mercado, disponibilidad de mano de obra, abas- 
tecimiento de energía y agua, disponibilidad de terrenos y clima, donde Lima obtuvo la calificación superior, seguida por Ica. En el análisis de microlocalización se tomaron como alternativas a Lurín, Puente Piedra y Chancay. Fueron evaluados los factores de cercanía a la materia prima, proximidad al mercado, disponibilidad de energía eléctrica y de agua, de vías de comunicación y de terreno. Puente Piedra logró la calificación más alta, seguido por Chancay. La localización del proyecto está ubicada en la Zona Industrial II, Las Vegas, en Puente Piedra.

\subsection{Ingeniería del producto}

La fórmula seleccionada para la pasta dental corresponde a la patente española para la composición de una pasta dentífrica, blanqueadora, antiplaca y antisarro de baja abrasividad fabricada con papaína. En la tabla 4 se detallan los porcentajes en peso de cada ingrediente.

Tabla 4

Formulación del producto en estudio

\begin{tabular}{llc}
\hline \multicolumn{1}{c}{ Componentes } & \multicolumn{1}{c}{ Insumo seleccionado } & \% en peso \\
\hline Abrasivo & Sílice coloidal pirogénica precipitada & 17,150 \\
Aditivos & Pirofosfato tetrasódico & 3,700 \\
Aditivos & Dihidrógeno porifosfato disódico & 2,300 \\
Aditivos & Dióxido de titanio & 0,100 \\
Aglutinante & Goma de tragacanto & 0,100 \\
Aromatizante & Aroma de menta & 1,000 \\
Colorante & Azul brillante FCF & 0,003 \\
Conservante & Metilparabeno & 0,150 \\
Edulcorante & Sacarina sódica o ciclamato sódico & 0,130 \\
Enzima & Papaína (6000 USP-U/mg) & 5,000 \\
Fluoruros & Fluoruro sódico & 0,320 \\
Humectante & Agua & 22,000 \\
Humectante & Xilitol & 6,000 \\
Humectante & Glicerina & 41,177 \\
Tensiactivo & Laurilsarcosinato sódico & 0,870 \\
\hline
\end{tabular}

Fuente: Álvarez (1996)

Elaboración propia 
Además, se seleccionó tecnología disponible y adecuada para la fabricación del producto: un sistema de ósmosis inversa para el tratamiento de agua; limpieza de tubos mediante el uso de un generador de ozono; premezcla y mezcla de la pasta con una mezcladora al vacío y la adquisición de maquinaria para el llenado y sellado de tubos.

A continuación se detallan las especificaciones técnicas del producto terminado:

Tabla 5

Especificaciones del producto

\begin{tabular}{ll}
\hline \multicolumn{1}{c}{ Producto } & \multicolumn{1}{c}{ Pasta dental fabricada con papaína } \\
\hline Empaque & Tubo y tapa de polipropileno \\
Etiqueta & Diseño en la superficie del tubo y la caja \\
Contenido neto & Pasta dental: $90 \mathrm{~g}$, y de papaína: $4,5 \mathrm{~g}$ \\
Embalaje & Caja de cartón \\
Unidad de comercialización & Cajas que contienen 126 cajas pequeñas \\
Indicaciones & - Mantener fuera del alcance de niños menores de 6 años, \\
& a menos que sea recomendado por un odontólogo. \\
& La aplicación o uso de los agentes fluorurados no \\
& desarrollo de la placa bacteriana. Visite a un odontólogo. \\
pH & Aproximadamente 7 \\
Autorización sanitaria & A través de la Digemid \\
\hline
\end{tabular}

Elaboración propia

\subsection{Normativa vigente relacionada con pastas dentales}

La legislación peruana cuenta con dos documentos relacionados con pastas dentales. La primera normativa, mencionada en la tabla 6, clasifica el producto en estudio como medicamento, ya que cuenta con más de 1100 ppm de flúor, motivo por el cual deberá indicarse en el empaque que su uso corresponde a niños mayores de seis años y adultos. La segunda explica los tres niveles de medicamentos comercializados en el país. El producto en estudio corresponde a la categoría 2, es decir, si bien es considerado como un medicamento, este no requiere receta 
médica para su venta. Sin embargo, como se espera que dicho producto sea vendido de forma libre, como las otras pastas dentales, se tramitará la certificación de uso de productos farmacéuticos, dispositivos médicos y productos sanitarios de libre venta (CPP).

Tabla 6

Normativa vigente aplicable al producto en estudio

\begin{tabular}{ll}
\multicolumn{1}{c}{ Normas vigentes } & \multicolumn{1}{c}{ Descripción } \\
\hline $\begin{array}{l}\text { Resolución Ministerial } \\
\text { N. }{ }^{\circ} \text { 454-2001-SA/DM }\end{array}$ & $\begin{array}{l}\text { Se aprueba la norma técnica sanitaria para } \\
\text { la adición de fluoruros en cremas dentales, } \\
\text { enjuagatorios y otros productos utilizados } \\
\text { en la higiene bucal. }\end{array}$ \\
$\begin{array}{l}\text { Decreto Supremo } \\
\text { N. } .^{\circ} \text { 016-2011-MINSA } \\
\text { y su modificatoria, } \\
\text { Decreto Supremo N. } \\
\text { 001-2012-MINSA }\end{array}$ & $\begin{array}{l}\text { Se aprueba el reglamento para el registro, } \\
\text { control y vigilancia sanitaria de productos } \\
\text { farmacéuticos, dispositivos médicos }\end{array}$ \\
\hline
\end{tabular}

Elaboración propia

\subsection{Capacidad de planta}

Con base en el balance de materia realizado, en los valores determinados como producción por hora de máquinas u operarios, y considerando que se trabaja un turno por día, ocho horas por turno, seis días a la semana, con una utilización de 0.982 y una eficiencia de 0.875 , se identificó la operación de encajonado y embalado como el cuello de botella, debido a que su capacidad de producción en unidades de producto terminado es de 84000 tubos por semana, como se muestra en la tabla 7 .

\subsection{Gestión del aseguramiento y control de la calidad}

Para garantizar la calidad de los insumos que ingresarán al proceso se utilizará la técnica de análisis sensorial, mientras que para asegurar la calidad e inocuidad del producto se implementará el sistema de análisis de peligros y puntos críticos de control (APPCC), así como las buenas prácticas de manufactura (BPM) y el programa operacional de saneamiento e higiene (POES). Cabe resaltar que todas las pruebas a lo largo del proceso productivo serán de tipo destructivas. 
Estudio para instalar una planta de producción de pasta dental utilizando papaína

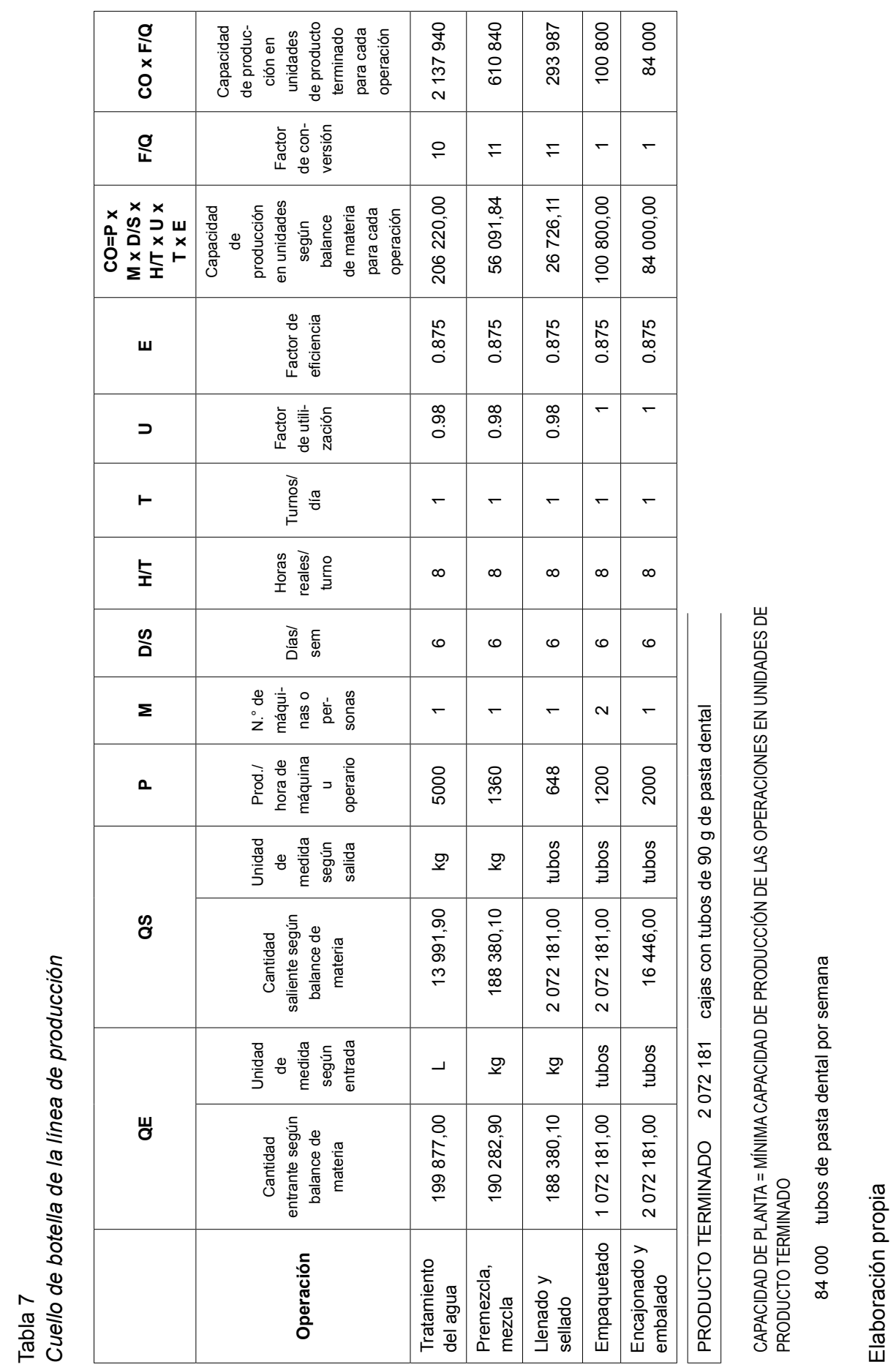


Tabla 8

Análisis de puntos críticos de la producción de pasta dental

\begin{tabular}{|c|c|c|c|c|c|c|}
\hline PPC & $\begin{array}{c}\text { Peligros } \\
\text { significativos }\end{array}$ & $\begin{array}{l}\text { Límites } \\
\text { críticos }\end{array}$ & Qué & Cómo & Cuándo & Quién \\
\hline \multirow{3}{*}{$\begin{array}{l}\text { Tratamiento } \\
\text { de agua }\end{array}$} & $\begin{array}{l}\text { Presencia de } \\
\text { organismos } \\
\text { contaminantes }\end{array}$ & $\mathrm{DBO}<1 \mathrm{ppm}$ & \multirow{3}{*}{$\begin{array}{c}\text { Control } \\
\text { de calidad } \\
\text { del agua }\end{array}$} & \multirow{3}{*}{ Muestreo } & \multirow{3}{*}{$\begin{array}{c}\text { Posterior al } \\
\text { tratamiento } \\
\text { de agua }\end{array}$} & \multirow{3}{*}{$\begin{array}{l}\text { Asistente de } \\
\text { laboratorio }\end{array}$} \\
\hline & Dureza de agua & $<6 \mathrm{ppm}$ & & & & \\
\hline & $\begin{array}{l}\text { Alta concentra- } \\
\text { ción de cloruros }\end{array}$ & $<2 \mathrm{ppm}$ & & & & \\
\hline \multirow{3}{*}{$\begin{array}{l}\text { Premezclado } \\
\text { y mezclado }\end{array}$} & Variación de PH & $\begin{array}{c}\text { Entre } 6.5 \\
\text { y } 7.5\end{array}$ & $\begin{array}{c}\text { Control } \\
\text { de calidad }\end{array}$ & Muestreo & $\begin{array}{l}\text { Durante el } \\
\text { proceso }\end{array}$ & $\begin{array}{l}\text { Asistente } \\
\text { de asegura- } \\
\text { miento de la } \\
\text { calidad }\end{array}$ \\
\hline & Temperatura & $18^{\circ} \mathrm{C}+-0,5^{\circ} \mathrm{C}$ & $\begin{array}{c}\text { Control } \\
\text { de calidad }\end{array}$ & Muestreo & $\begin{array}{c}\text { Durante el } \\
\text { proceso }\end{array}$ & $\begin{array}{l}\text { Asistente } \\
\text { de asegura- } \\
\text { miento de la } \\
\text { calidad }\end{array}$ \\
\hline & Viscosidad & $\begin{array}{c}70000 \mathrm{a} \\
100000 \mathrm{pc}\end{array}$ & $\begin{array}{c}\text { Control } \\
\text { de calidad }\end{array}$ & Muestreo & $\begin{array}{l}\text { Durante el } \\
\text { proceso }\end{array}$ & $\begin{array}{c}\text { Asistente } \\
\text { de asegura- } \\
\text { miento de la } \\
\text { calidad }\end{array}$ \\
\hline $\begin{array}{l}\text { Llenado y } \\
\text { sellado de } \\
\text { tubos }\end{array}$ & $\begin{array}{l}\text { Variación del } \\
\text { peso del pro- } \\
\text { ducto terminado } \\
\text { por aire ocluido }\end{array}$ & $\begin{array}{c}\text { Peso del } \\
\text { producto } \\
\text { debe ser } 90 \mathrm{~g} \\
+-0,2 \mathrm{~g}\end{array}$ & $\begin{array}{c}\text { Control } \\
\text { de calidad }\end{array}$ & Muestreo & $\begin{array}{l}\text { Posterior al } \\
\text { Ilenado y } \\
\text { sellado }\end{array}$ & $\begin{array}{l}\text { Asistente } \\
\text { de asegura- } \\
\text { miento de la } \\
\text { calidad }\end{array}$ \\
\hline
\end{tabular}

Elaboración propia

Adicionalmente, se plantea realizar auditorías internas y externas con base en los criterios de calificación del Premio Deming, debido a la ponderación equitativa sobre todos sus criterios, evaluando el desempeño de la organización no solo por resultados a corto plazo.

\subsection{Gestión del medio ambiente}

A partir de la matriz de causa-efecto realizada, se determinó que el proyecto representa un riesgo moderado-bajo para su entorno. Durante la principal etapa del proyecto, la de operaciones, el impacto positivo más importante es la generación de fuentes de empleo, mientras que la contaminación por ruido se identificó como el de mayor impacto negativo. Cabe mencionar que el proyecto incluye la construcción de una planta de tratamiento de efluentes. 


\subsection{Gestión de seguridad y salud en el trabajo}

El proyecto considera como uno de sus principales objetivos la seguridad y la salud de sus colaboradores. En ese sentido, no solo se espera cumplir con los requerimientos de la normativa vigente sino lograr un entorno de trabajo positivo y proactivo. Todos los colaboradores serán capacitados para identificar los peligros y riesgos de sus actividades, lo que permitirá contar con una matriz IPER permanentemente actualizada. A la vez, esta servirá como base para la ejecución de procedimientos de trabajo seguro, los mismos que serán utilizados para inducir a los nuevos integrantes de la organización.

\subsection{Gestión del mantenimiento}

En cuanto a mantenimiento, se realizará el de tipo preventivo para los principales equipos y sistemas, y el de tipo correctivo para los dispositivos que no representen riesgos al personal, y cuyo precio de compra sea menor al costo de su mantenimiento.

\subsection{Programa de producción}

Con base en el estudio de mercado realizado, la evolución de la marca Dento desde que ingresó al mercado peruano, y un porcentaje de riesgo a fin de satisfacer la posición moderada de los inversionistas, se determinó la participación del mercado esperada (tabla 9).

Tabla 9

Cálculo de la participación de mercado esperada

\begin{tabular}{cccc}
\hline Año & $\begin{array}{c}\text { Porcentaje de } \\
\text { participación de } \\
\text { mercado estimada }\end{array}$ & $\begin{array}{c}\text { Porcentaje } \\
\text { Intradevco (Dento) }\end{array}$ & $\begin{array}{c}\text { Porcentaje de } \\
\text { participación de } \\
\text { mercado esperada }\end{array}$ \\
\hline 2012 & 3,53 & 2,99 & 1,50 \\
2013 & 3,53 & 3,32 & 2,01 \\
2014 & 3,53 & 3,65 & 2,52 \\
2015 & 3,53 & 3,99 & 3,02 \\
\hline 2016 & 3,53 & 4,32 & 3,53 \\
\hline
\end{tabular}

Elaboración propia 
Esta participación fue finalmente aplicada a la DIA del producto en estudio para obtener el programa de producción y la capacidad requerida (tabla 10).

Tabla 10

Cálculo del programa de producción y capacidad requerida

\begin{tabular}{ccccccc}
\hline Año & $\begin{array}{c}\text { Proyección } \\
\text { DIA (kg) }\end{array}$ & $\begin{array}{c}\text { Porcentaje de } \\
\text { participación } \\
\text { de mercado } \\
\text { esperada }\end{array}$ & $\begin{array}{c}\text { Programa de } \\
\text { producción } \\
\mathbf{( k g )}\end{array}$ & $\begin{array}{c}\text { Programa de } \\
\text { producción } \\
\text { (tubos) }\end{array}$ & $\begin{array}{c}\text { Capacidad } \\
\text { requerida } \\
\text { (kg) }\end{array}$ \\
\hline 2012 & 12433087,12 & 1,50 & 186496,31 & 2072181,19 & 192204,99 \\
2013 & 13063380,59 & 2,01 & 262247,37 & 2913859,62 & 270274,80 \\
2014 & 13693674,07 & 2,52 & 344395,90 & 3826621,14 & 354937,91 \\
2015 & 14323967,54 & 3,02 & 432941,92 & 4810465,76 & 446194,34 \\
\hline 2016 & 14954261,01 & 3,53 & 527885,41 & 5865393,49 & 544044,07 \\
\hline
\end{tabular}

Elaboración propia

\subsection{Aspectos económicos y financieros}

Las estimaciones de la inversión fija tangible, intangible y capital de trabajo se calcularon en su mayoría mediante el método de Peters \& Timmerhaus. Se partió del costo de la maquinaria y equipo, el cual fue calculado a partir de cotizaciones a distintos posibles proveedores, que dio un total de 591760 nuevos soles. Al sumar la inversión fija tangible y la intangible junto con el capital de trabajo resulta una inversión total de aproximadamente 4 millones de nuevos soles. En cuanto a la estructura de financiamiento, se ha optado por la del $30 \%$ en aporte propio y $70 \%$ en financiamiento, el cual se propone sea desarrollado con la Corporación Financiera de Desarrollo (Cofide), con una tasa de interés anual del $18 \%$.

En la industria farmacéutica, el precio ofrecido a los consumidores se incrementa por lo menos una vez al año, según la estrategia de cada empresa, por este motivo la presente investigación considera un incremento anual del precio del producto. Este guardará relación con la 
inflación en el país de 4,14 \% en el último año, según el Banco Central de Reserva del Perú. La tabla 11 muestra la proyección del precio al cliente final y al cliente directo, considerando un $4 \%$ de incremento de precio de venta al cliente final y un margen promedio de $39 \%$.

$\mathrm{Al}$ analizar ambos escenarios, es decir el flujo económico y el financiero, encontramos que los mayores VAN, TIR y beneficio costo son con el escenario financiero, para lo cual se tomó un TEA del $18 \%$, un COK de $24 \%$ y un CPPC de $20 \%$ (tablas $12,13,14$ y 15 ).

Tabla 11

Proyección precio de venta (S/.)

\begin{tabular}{lcccccc}
\hline Años & $\mathbf{2 0 1 2}$ & $\mathbf{2 0 1 3}$ & $\mathbf{2 0 1 4}$ & $\mathbf{2 0 1 5}$ & $\mathbf{2 0 1 6}$ & $\mathbf{2 0 1 7}$ \\
\hline Precio de venta al cliente final & 9,48 & 9,86 & 10,25 & 10.66 & 11.09 & 11.53 \\
Incremento de precio (\%) & & 4,00 & 4,00 & 4,00 & 4,00 & 4,00 \\
Margen canal de distribución (\%) & 39 & 39 & 39 & 39 & 39 & 39 \\
Precio al cliente directo & 6,81 & 7,09 & 7,37 & 7,67 & 7,97 & 8,29 \\
\hline
\end{tabular}

Elaboración propia

Tabla 12

Flujo de caja económico del proyecto

\begin{tabular}{|c|c|c|c|c|c|c|}
\hline Años & 0 & 1 & 2 & 3 & 4 & 5 \\
\hline $\begin{array}{l}\text { Flujo de caja } \\
\text { parcial }\end{array}$ & - & $-169743,82$ & $-549934,73$ & 1605162,37 & 3209082,93 & 5393247,49 \\
\hline $\begin{array}{l}\text { (-) Inversión } \\
\text { inicial }\end{array}$ & $-3724559,01$ & - & - & - & - & - \\
\hline$(+)$ Intereses & - & 469294,44 & 553767,43 & 447588,80 & 322 298,02 & 174454,89 \\
\hline FC económico & $-3724559,01$ & $-700449,38$ & 3832,70 & 2052751,17 & 3531380,95 & 5567702,38 \\
\hline
\end{tabular}

Elaboración propia 


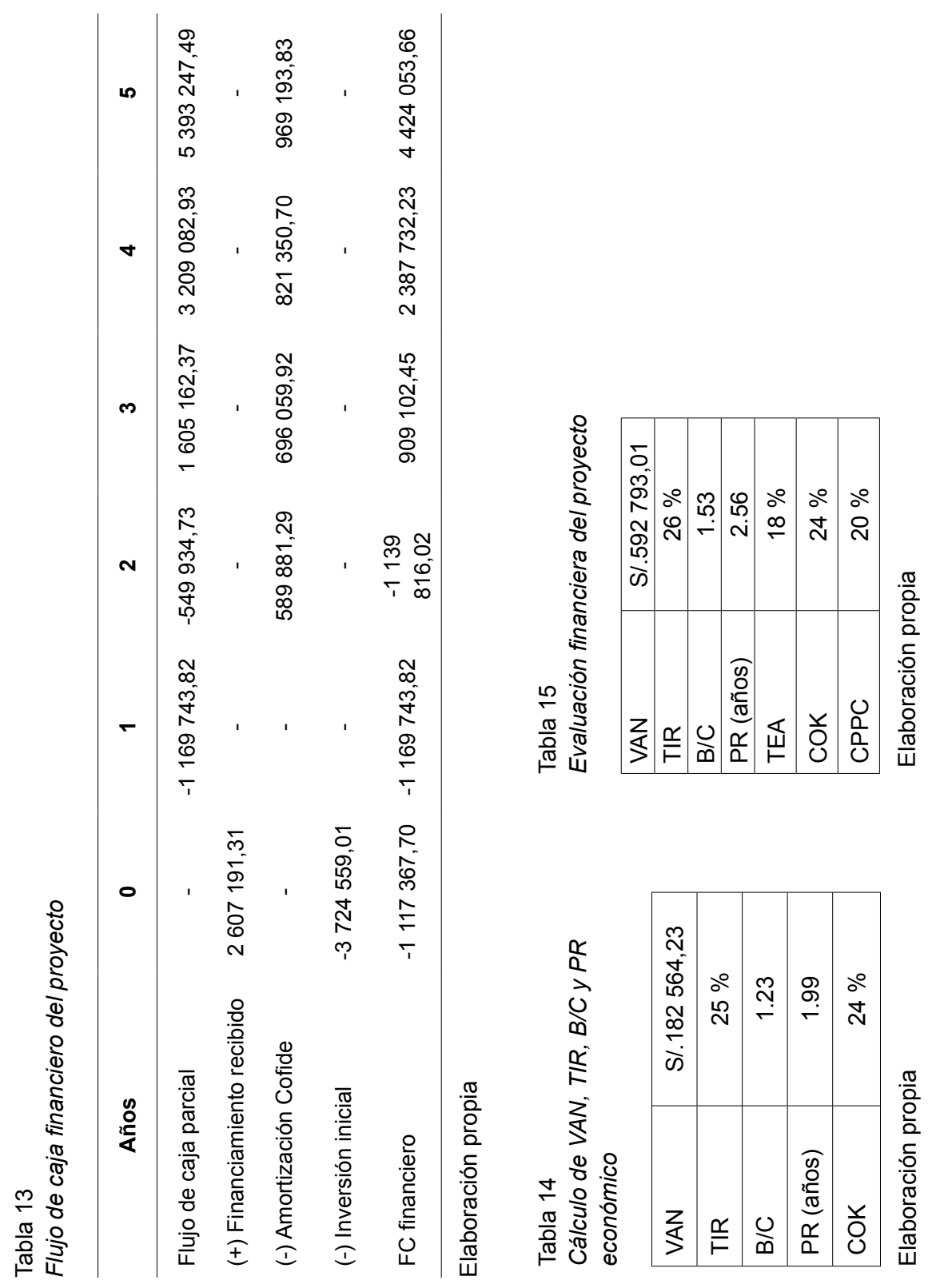




\subsection{Análisis de sensibilidad}

En el análisis de sensibilidad se manipularon las siguientes variables: precio de venta, volumen de venta, costo de oportunidad y tasa de préstamos, las cuales fueron alteradas en un rango de $+/-15 \%$, donde el precio de venta es la variable que afecta en mayor magnitud los indicadores financieros, de manera que si este disminuye en $15 \%$ el VAN sería de -S/. 8667003 y si aumenta en $15 \%$ el VAN del proyecto sería de $\mathrm{S} / .8232823$.

\section{CONCLUSIONES}

1. El estudio de mercado demostró que la comercialización del producto dirigido a los sectores socioeconómicos A y $\mathrm{B}$ de Lima metropolitana es viable; con la aplicación de una estrategia de diferenciación a partir del uso de la papaína para lograr una pasta dental blanqueadora, antiplaca y antisarro de baja abrasividad. Además, permitió estimar la demanda del producto equivalente a 4873765,28 tubos de 90 g para el primer año del proyecto.

2. Se demostró la viabilidad tecnológica del proyecto al complementar la formulación propuesta en la patente española para la composición de una pasta dentífrica, blanqueadora, antiplaca y antisarro de baja abrasividad fabricada con papaína, con la selección de la tecnología, la maquinaria y los equipos disponibles en el mercado, así como el sistema de aseguramiento y control de la calidad por aplicar al producto en estudio. Así, se concluyó que el proceso de purificación de agua debe realizarse mediante ósmosis inversa, ya que este cumple con los estándares más altos de calidad del agua, rechazando hasta más de un 99,9 \% de virus, bacterias y pirógenos, lo que permite garantizar la inocuidad del producto. Considerando lo antes mencionado, y cumpliendo con la proyección de ventas, se determinó una capacidad de 5241600 tubos para el primer año de operaciones.

3. La inversión estimada para la implementación del proyecto es de 3 724559 nuevos soles, del cual $30 \%$ es aporte propio y $70 \%$ proviene de la fuente financiera Cofide, utilizando el programa de inversión Probid. Asimismo, se calculó un TIR financiero de 26,4 \% y un VAN financiero de 592793 nuevos soles, concluyéndose que el proyecto es económicamente viable. 


\section{RECOMENDACIONES}

1. $\mathrm{Al}$ momento de implementar el proyecto se recomienda actualizar la información del estudio de mercado realizado, a fin de considerar los hábitos de consumo actuales del mercado objetivo y alinear las estrategias de marketing a los requerimientos del consumidor.

2. Si bien la patente española utilizada como base técnica representa una prueba válida de la eficiencia de la pasta dental en estudio, se recomienda realizar una evaluación de la efectividad de dicho procedimiento, con el objetivo de utilizar los resultados para fines comerciales. Asimismo, se recomienda realizar una nueva evaluación de proveedores nacionales e internacionales, tomando en cuenta los insumos sustitutos.

3. Se recomienda evaluar otras tasas de financiamiento, con el objetivo de lograr un costo financiero menor y aumentar la rentabilidad del proyecto.

\section{REFERENCIAS}

Álvarez, M. (1996). Pasta dentrifica, blanqueadora, antiplaca y antisarro de baja abrasividad (traducción de patente europea). Madrid: Oficina Española de Patentes y Marcas.

Bettina, A. (2006). Importancia de la salud oral y su conexión con la salud general. Biomedicina, 2(3), 246-251.

Bonilla, V., Mantín, J., Jiménez, A., y Llamas, R. (2007). Alteraciones del color de los dientes. REDOE. Recuperado de http://redoe. wordpress.com/2007/02/21/alteraciones-del-color-de-los-dientes/

Casto, V. M. (2005). Inhibición del crecimiento In vitro de Streptococcus mutans por Papaina y Sanitrend. (Trabajo de investigación para optar al título de cirujano-dentista). Universidad de Chile. Chile.

Chullén, F. (2010). La utilización de la papaína en la industria. Recuperado de http://www.carrerasconfuturo.com/2010/08/19/lautilizacion-de-la-papaina-en-la-industria/

Favero, J., Bernal, N., y Yácono, J. C. (2008). Diseño de un proceso experimental para la producción de papaína liofilizada. Revista de la Facultad de Ingeniería Industrial, 10(26), 177-193. 
Ipsos Apoyo. (2011). Estadística poblacional 2011. Lima: Ipsos Apoyo. Johannsen, G., Tellefsen, G., Johannsen, A., y Liljeborg, A. (2013). The importance of measuring toothpaste abrasivity in both a quantitative and qualitative way. Acta Odontologica Scandinavica, 71(3-4), 508-517.

Linares, A., y Morales, R. (2014). Estudio para la instalación de una planta de producción de pasta dental utilizando papaína como ingrediente activo. (Tesis para obtener el título de ingeniero industrial). Universidad de Lima. Perú.

Ministerio de la Producción. (2012). Anuario Estadístico 2011.Oficina General de Tecnología de la Información y Estadística. Recuperado de http://www.produce.gob.pe

Ministerio de Salud del Perú, Dirección General de Salud de las Personas. (2011). Salud bucal. Recuperado de http://www.minsa. gob.pe/portada/est_san/saludbucal.htm

Mundo, J., y Serrano, D. (2012). Extracción de la enzima papaína del látex de Carica papaya cultivado en el país y su aplicación en cicatrices tipo queloide y verrugas. (Trabajo para optar al grado de Licenciatura en Química y Farmacia). Universidad de El Salvador. El Salvador.

Organización Mundial de la Salud. (2006). Salud bucodental: plan de acción para la promoción y la prevención integrada de la morbilidad. Recuperado de http://www.who.int/es

Organización Mundial de la Salud. (2010). Estadísticas sanitarias mundiales. Personal sanitario, infraestructura y medicamentos esenciales. Recuperado de http://www.who.int/es

Sigma Aldrich. (8 de marzo de 2013). Papain. Analytical enzymes. Recuperado de http://www.sigmaaldrich.com

Sunat. (2012). Importaciones de pasta dental del 2007 al 2011. Recuperado de base de datos Datatrade.

Vásquez, F. J. (1989). Estudio tecnológico para la fabricación de pasta dental. (Tesis para optar el título de ingeniero industrial). Universidad de Lima. Perú. 
